those who did not get PS, which seems to supports the stricter enforcement of the guidelines.

\section{PO-0738 PROLONGED RESPIRATORY SUPPORT FOR EXTREME PRETERM BABIES: HHFNC OR NCPAP?}

A Gupta, AA Abdelhamid, C Harikumar, S Gupta. Paediatrics, University Hospital of North Tees, STOCKTON on TEES, UK

\subsection{6/archdischild-2014-307384.1378}

Background and aims While the HHFNC therapy is increasingly being utilised for non-invasive respiratory support in preterm babies its utility has not been explored in babies requiring prolonged support.

We carried out this study to compare the effectiveness of HHFNC therapy with nCPAP in babies requiring prolonged respiratory support.

Design/methods This was a retrospective study of babies less than 32 weeks gestation or 1500 gram requiring prolonged respiratory care. In order to be eligible for inclusion, the baby should have come off nCPAP successfully to low flow oxygen and needed non-invasive breathing support using nCPAP or HHFNC.

Results Complete data was available for 44 babies. Babies in HHFNC group spent significantly longer time on respiratory support. There was no difference in BPD and other complications of prematurity between two study groups (Table 2)

Conclusion HHFNC therapy is comparable to nCPAP but probably at the expense of prolonged duration of respiratory support.

\begin{tabular}{llll}
$\begin{array}{l}\text { Abstract PO-0738 Table } 1 \\
\text { (IQR) }\end{array}$ & Respiratory parameters - Median \\
\hline & nCPAP $(n=22)$ & HHFNC $(n=20)$ & p-value \\
\hline Initial MV (hours) & $132(84-222)$ & $84(60-135)$ & 0.06 \\
Initial CPAP (hours) & $108(60-156)$ & $60(36-114)$ & 0.11 \\
Post weaning CPAP+HHFNC (hours) & $312(150-510)$ & $636(372-768)$ & 0.003 \\
Low flow/Oxygen therapy (hours) & $684(396-1014)$ & $552(366-888)$ & 0.6 \\
\hline
\end{tabular}

\section{Abstract P0-0738 Table 2}

\begin{tabular}{llll}
\hline & nCPAP $(n=22)$ & HHFNC $(n=20)$ & p value \\
\hline Broncho-pulmonary-Dysplasia & $14(64 \%)$ & $16(80 \%)$ & 0.24 \\
NEC $\geq 2$ a & $4(18 \%)$ & $3(15 \%)$ & 0.78 \\
IVH $3 / 4$ & $0(0 \%)$ & $1(5 \%)$ & 0.28 \\
ROP stage 2 or more & $9(41 \%)$ & $4(20 \%)$ & 0.14 \\
Change in weight z score - mean (SD) & $-1.11(0.83)$ & $-0.82(0.89)$ & 0.23 \\
\hline
\end{tabular}

\section{P0-0739 AN UNUSUAL CASE OF NEONATAL RESPIRATORY DISTRESS : CASE REPORT}

H Besbès ${ }^{1},{ }^{2} \mathrm{H}$ Mhabrech, ${ }^{2} \mathrm{~A}$ Zrigue, ${ }^{3} \mathrm{~K}$ Ben Ameur, ${ }^{3} \mathrm{~K}$ Monastiri, ${ }^{1} \mathrm{~S}$ Hammami, ${ }^{2} \mathrm{CH}$ Hafsa. ${ }^{1}$ Pediatric, Fattouma Bourguiba Hospital, Monastir, Tunisia; ${ }^{2}$ Radiology, Fattouma Bourguiba Hospital, Monastir, Tunisia; ${ }^{3}$ Neonatology, Fattouma Bourguiba Hospital, Monastir, Tunisia

10.1136/archdischild-2014-307384.1379
Background Neurenteric cysts are the association of an endodermal cyst with a vertebral dysplasia. This congenital malformation can be asymptomatic or manifest itself through respiratory signs due to airway compression.

Case report A male newborn, from normal vaginal delivery at 40 weeks of gestation, weighing $4000 \mathrm{~g}$ with Apgar score of 8 and 9 at 1 and $5 \mathrm{~min}$ was referred to the neonate intensive care unit. The clinical findings showed tachypnea, mild intercostals retraction and there was diminished air-entry on the right side. The chest X-ray showed vertebral anomalies in the midthoracic region, there was an hydric opacity occupying the $2: 3$ of the right side with deviation of the mediastinum to the left side. The CT scan of the chest revealed butterfly and hemi-vertebrae of the upper thorax. There was a large posterior mediastinal cystic mass partitioned by multiple septa on the inferior right side. On fifth day, the patient underwent a right thoracotomy. A large cystic mass attached to the oesophagus wall was exised, Histopathology favours the diagnosis of neurenteric cyst. Postoperatively outcomes were poor, the operation was complicated by bilateral chylothorax diagnosed on 10 th post-operative day and increasing oxygen needs. The newborn died on the 16 th postoperative day in a severe sepsis.

Conlusion Antenatal diagnosis of this malformation is not easy but possible. In post-natal, the radiological approach based on chest x-ray and CT scan, is helpful for establishing the diagnosis and lead to a prompt curative surgery.

\section{PO-0740 WITHDRAWN}

\section{P0-0741 CROSSOVER TRIAL COMPARING HIGH-FREQUENCY OSCILLATORY VENTILATION VERSUS VOLUME GUARANTEE PLUS HIGH-FREQUENCY OSCILLATORY VENTILATION: A PRELIMINARY REPORT}

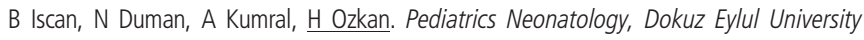
Faculty of Medicine, Izmir, Turkey

\subsection{6/archdischild-2014-307384.1380}

Background High frequency oscillatory ventilation (HFOV) theorically limits baro/volutrauma using subdeadspace volumes but lack of direct control over tidal volume resulting in fluctuating PCO2 level. Volume guarantee plus high-frequency oscillatory ventilation $(\mathrm{HFOV}+\mathrm{VG})$ is a new ventilation mode allows the clinician to set a mean tidal volume to be delivered.

Method The randomised, crossover study was conducted at the Neonatal Intensive Care Unit (NICU) at Dokuz Eylul University Hospital in Izmir, Turkey after approval of the local Ethics Committee. Inborn infants at less than 32 weeks of gestation with respiratory distress syndrome (RDS) were enrolled in the study if they required mechanical ventilation. All enrolled infants were received surfactant treatment $(200 \mathrm{mg} / \mathrm{kg}$, Curosurf $\AA$, Chiesi, Italy) in the delivery room or in the NICU, depending on where endotracheal intubation was performed and ventilated using the Assist Control (A/C) with VG mode (VN500, Draeger, Lubeck, Germany). Patients were randomised to receive either HFOV $+\mathrm{VG}$ or HFOV as the initial ventilator mode and were treated for $2 \mathrm{~h}$ with the first mode of ventilation. At the end of the initial $2 \mathrm{~h}$ patients were then crossed over to the other mode of ventilation for $2 \mathrm{~h}$. There was $15 \mathrm{~min}$ "washout" period between the changes in the ventilator modes. HFOV was performed with "optimum volume strategy". Ventilation started at a frequency of 